\title{
Luminal subtypes and response to neoadjuvant chemotherapy for hormone receptor-positive HER2-negative patients
}

\author{
Kadri Altundag ${ }^{1}$ (D)
}

Received: 3 August 2020 / Accepted: 13 August 2020 / Published online: 4 September 2020

๑) Springer Science+Business Media, LLC, part of Springer Nature 2020

To the editor,

I wish to congratulate Zeidman and their colleagues [1] for their article in which they explored utility of neoadjuvant chemotherapy (NAC) for hormone receptor-positive HER2negative (HR+ HER2-) patients. Among 134,574 patients, 105,324 (78\%) had adjuvant chemotherapy (AC) and 29,250 (22\%) received NAC. They found that NAC use among HR+ HER2 - breast cancer patients has expanded over time and offers downstaging of disease for some patients, with $\mathrm{pCR}$ seen in only a small subset (8.3\%), but downstaging of the axilla in $21 \%$. They concluded that more studies are needed to explore these findings and better predict patients who would be excellent responders. The authors did not analyze response rates of patients according to luminal subtypes. The St. Gallen International Expert Consensus 2013 defined luminal A as ER-positive, HER2-negative, Ki-67 low, and PR high and Luminal B as ER-positive, HER2-negative, and either Ki-67 high or PR low [2]. Haque et al. [3] analyzed response rates and $\mathrm{pCR}$ by breast cancer molecular subtype following NAC. Among ER-positive breast cancer patients, $322(2 \%)$ cases and $5941(43 \%)$ cases were luminal A and luminal B. Compared with luminal A, luminal B was nearly 30 times more likely to achieve pCR. Interestingly, the overall pCR rate was only $0.3 \%$ in luminal A disease. Taken all together, luminal subtype B might be better predictive marker showing greater response to NAC. This issue merits further investigation.

Kadri Altundag

altundag66@yahoo.com

1 MKA Breast Cancer Clinic, Tepe Prime, Cankaya, 06800 Ankara, Turkey
Funding No funding.

\section{Compliance with ethical standards}

Conflict of interest I declare that I have no conflict of interest.

Ethical approval Not applicable.

Informed consent Not applicable.

Research involving human or animals participants This article does not contain any studies with human participants or animals performed by any of the authors.

\section{References}

1. Zeidman M, Alberty-Oller JJ, Ru M et al (2020) Use of neoadjuvant versus adjuvant chemotherapy for hormone receptor-positive breast cancer: a National Cancer Database (NCDB) study. Breast Cancer Res Treat. https://doi.org/10.1007/s10549-020-05809-w

2. Goldhirsch A, Winer EP, Coates AS et al (2013) Panel members Personalizing the treatment of women with early breast cancer: highlights of the St Gallen International Expert Consensus on the Primary Therapy of Early Breast Cancer 2013. Ann Oncol 24:2206-2223

3. Haque W, Verma V, Hatch S (2018) Response rates and pathologic complete response by breast cancer molecular subtype following neoadjuvant chemotherapy. Breast Cancer Res Treat 170:559-567

Publisher's Note Springer Nature remains neutral with regard to jurisdictional claims in published maps and institutional affiliations. 